\title{
The Power of the Periphery: Reassessing Spatial Metaphors in the Ideological Positioning of the Translator
}

\author{
Liz Medendorp \\ Pikes Peak Community College
}

In drawing attention to the "intricate mechanisms underlying the translation activity in its societal context," Michaela Wolf notes that the "sociological turn" of translation studies has shifted focus away from the translation to the translator (130). This shift is primarily concerned with foregrounding the translator's cultural and societal situatedness and its implications for the translation process. A reconceptualization of the positionality in translation that accounts for this contextual embeddedness and conditioning is therefore crucial to the discipline today. Yet positionality within the context of translation is a problematic concept precisely because "translation as an activity is always doubly [or multiply] contextualized, since the text has a place in two [or more] cultures" (Bassnett and Lefevere11).To grapple with these complexities, the translator's position is most often framed in terms of spatial metaphors that employ illustrative concepts such as periphery and margin, in between, migration and travel, contact zones and border cultures. This list is nowhere near exhaustive, ${ }^{1}$ but it might be considered representative of the kinds of expressions generally accepted and employed by the scholarly translation community. These and many other evocative spatial metaphors often seem to be used primarily for their aesthetic value because they are frequently employed without sufficient critical scrutiny. To be sure, these metaphors provide useful insights when conceptualizing the translator's position, yet none are without their problems. In order to better understand the impact a translator's cultural embeddedness has on the translation process, a more nuanced consideration of the translator's positionality is needed.

Whether explicitly referring to the "margin" of one culture or a "border" "between" cultures, the vast majority of commonly used spatial metaphors locate translation at the edge, the extremity, or the periphery of a cultural construct. The peripheral metaphor is therefore a useful starting point. When conceived in this way, translation is perceived to be as close to the outside, to "otherness," as possible. Although translation necessarily

\footnotetext{
${ }^{1}$ For a much more thorough exploration of the wide range of metaphors used to describe the translation process, see the volume edited by James St. André, Thinking through Translation with Metaphors (2010).
} 
involves an encounter with otherness, it need not be a peripheral activity. Submitting to the view that "translation is interesting precisely because it is a marginal activity, one that has been made to occupy a lesser and peripheral position in the hierarchy of expression" (Gruesz 89) only perpetuates the tradition of translation's subordination as a derivative or inferior activity. In fact, referring to translation in this peripheral sense belies the ubiquity and essentiality of translation in the modern world. Moreover, although the marginalization of translation is indeed an interesting phenomenon, marginality is not necessarily an intrinsic characteristic of translation but rather a conventional label historically ascribed to it.

The idea of the periphery is a common component in the many different ways the translator's position has been conceptualized, but it demonstrates how positioning translation in terms of spatial metaphors in this way reinforces deep-seated structures of power and hegemony that have long afflicted not just translation but all forms of intercultural encounter. Although perceived as somehow subordinate to the "centre," the periphery is actually a position of greater power in terms of the ability to effect change and influence cultural systems because of the encounter with "otherness" implicated in the experience of the periphery. What is interesting about translation, therefore, is not its supposed inherent marginality, as Gruesz's claim suggests. Rather, translation is interesting because, through its confrontation with otherness, it elicits a reexamination of the Self. Ideally, then, the term "periphery" should not refer to translation's status within the hierarchies of disciplines or modes of expression, nor should it be used to frame the position of the translator itself. Instead, the "periphery" is a more useful metaphor when it is associated with the space where encounters with otherness take place.

\section{Framing Positionality: A Conditioned and Subjective Ideological Perspective}

It is important to preface an examination of the spatial metaphors frequently employed in discussions of translation and positionality with a consideration of how the term "positionality" is being framed here. At the core, the translator's position refers to his or her "space" (cf. Bhabha54-56) or "place" (Ibid. 281) of enunciation, which is "an ideological positioning as well as a geographical or temporal one" (Tymoczko 183). Put simply, the translator's place of enunciation constitutes the ideological perspective from which he or she speaks, which is conditioned by linguistic, cultural, and societal contexts 
and individuated through subjective experiences. Although an individual's ideological perspective is necessarily subjective, it is conditioned by the babitus, an internalized "system of lasting, transposable dispositions which, integrating past experiences, functions at every moment as a matrix of perceptions, appreciations, and actions and makes possible the achievement of infinitely diversified tasks" (Bourdieu82-83, his emphasis).

These deeply encoded shared dispositions are fundamentally constructed for each individual through personal encounters with the conventions of the habitus and develop through networks of contextual affiliations (heritage, linguistic background, hometown, family traditions, friendships, mentors, education, and so on). In Clifford Geertz's view, since "man is an animal suspended in webs of significance he himself has spun" (5) those webs of significance (or networks of affiliations) constitute the very essence of culture itself. For members of a given habitus, then, we can presume that these webs of significance largely overlap from individual to individual. At the same time, shades of difference are rooted in subjective experiences that vary just enough to make each person's ideological perspective, while grounded in collective dispositions, unique. Those practices that lie most firmly in areas of overlap between members' webs of significance contribute to the ideological stance of the habitus.

Positionality is therefore formulated through a communal system of intelligibility, but the dispositions and conditioned practices that characterize the habitus do not obviate the existence of subjective experience or the possibility of non-normative behaviour. The aggregate of the diverse perspectives and behaviours of the community thus results in a highly complex system that is dynamic and fluid, especially at the periphery, and also contains a relatively stable, but not permanently fixed, core ideology implicitly agreed upon by the majority. The construction of this peripherally indeterminate but centrally stable habitus is a collective, culturally conditioned, and continuous process that situates the translator within a specific but open ideological perspective.

The translator therefore necessarily translates from a subjective ideological perspective conditioned by the collectively constructed ideological system of the habitus. Considering this strong ideological charge inherent to the translator's position, it is curious that the prevailing discourse would frame positionality in terms of spatial metaphors rather than as an ideological construct that does not necessarily correspond to an actual physical space occupied by the translator. This curiosity may be partially 
attributed to residual associations from earlier times; the word "translation" is itself rooted in the idea of physical movement (from the Latin translatio, "to carry across"), initially connoting the transportation of relics of the saints but also later of information and ideas. Such historical associations with physical travel may contribute to the tendency to represent positionality within the context of translation with spatial metaphors. $^{2}$

Because the movement of information and ideas is now liberated from a contingency upon material transportation, it may no longer be theoretically useful to approach positionality in such concrete spatial terms. Just as the act of translation extends a text's "afterlife" (cf. Benjamin 1969) by restoring it to relevance in a new context, we must similarly renew our understanding of the translator's position to make it relevant in an age when the flow of information, and thus the translator him/herself, is no longer physically bound to a singular place, cultural framework, or linguistic mode of constructing the world. Rather than wholly dismissing the existing body of spatial metaphors that constitute our "original" text, however, it is prudent first to examine how the images of positionality they espouse have historically pervaded and contributed to translation theory and how they might offer newly productive insights for theorizing the problematic position of the translator.

\section{Systems Theory}

Having already contributed some of its concepts and terminology to framing the ideological positioning of the translator, systems theory emerges as a potentially useful framework for interrogating the spatial metaphors at hand. Moreover, the way in which the term "periphery" is used in systems theory is less problematic to conceptualizing an ideological rather than spatial idea of positionality. Although a comprehensive discussion of systems theory is not possible within the scope of this study, a brief overview of some of its overriding principles provides a highly productive framework for our consideration of positionality. At a very basic level, systems are "networks of relations that can be hypothesized for a certain set of assumed observables ('occurences'/'phenomena')"

\footnotetext{
${ }^{2}$ See Maria Tymoczko's contribution to Thinking Through Translation with Metaphors (St. André 2010) for an examination of the persisting literalism with which this metaphorical conceptualization is applied to translation studies.
} 
(Even-Zohar 2010:40). Bourdieu's habitus, for example, might justifiably be identified as a system because it is constructed out of networks of affiliations, or "webs of significance," and is more or less stable across experiences. ${ }^{3}$

More broadly speaking, systems theory reflects the complex interrelations between linguistic, cultural, and ideological contexts inherent to the translator's multiple affiliations precisely because systems "are not homogenous entities but are always plural and open, in the sense that they are systems of systems, and systems within systems" (Pym116). Any given system is therefore inevitably interwoven with other systems. Itamar Even-Zohar's seminal body of work on polysystems, ${ }^{4}$ for example, is primarily concerned with literary systems, but it acknowledges that this type of system is necessarily related to other systems of language, culture, economics, politics, and so forth. Systems are therefore dynamic structures because such plurality, openness, and interconnectivity results in a flow of ideas, conventions, and practices through interrelated systems, inducing change within their webs of significance.

\section{World-Systems Theory}

Expanding our consideration of systems to a global scale, the related school of thought known as "world-systems theory" 5 demonstrates how the movements of difference and power have worldwide effects. Particularly within the context of globalization, a global

\footnotetext{
${ }^{3}$ Although the habitus provides a convenient illustration of the concept of a system because it has already been discussed in the context of this study, it is perhaps a somewhat misleading example. Whereas there is no conscious awareness of the habitus because this type of system is wholly internalized, systems in the more general sense are not necessarily relegated to the subconscious in this way. Encounters with otherness and the resulting reexamination of the Self cause a temporary awakening to the systemic construct of the habitus, but this awareness is only fleeting as it subsequently leads to re-conditioning within a re-tooled habitus that becomes similarly internalized.

${ }^{4}$ Although "systems theory" is now the generally accepted term, Even-Zohar's work on "polysystem theory," first presented in his 1978 Papers in Historical Poetics and later expounded in further texts (cf. 1990; 2010), arguably represents the primary theoretical foundations for systems theory today. Moreover, as Even-Zohar is most commonly and directly credited with developing the framework of the "system," I therefore primarily employ his theories here, particularly with regard to his conceptualization of the "center" and "periphery."

${ }^{5}$ For an excellent introduction to world-systems theory, particularly as informed by ideas surrounding the phenomenon of globalization, see the volume edited by Anthony D. King Culture, Globalization and the World-System: Contemporary Conditions for the Representation of Identity (1997), especially the contributions of Immanuel Wallerstein and Ulf Hannerz.
} 
perspective on systems theory exposes further aspects of positionality as a relevant theoretical concept for the current age. The concept of the world-system is most explicitly defined as

a social system, one that has boundaries, structures, member groups, rules of legitimation, and coherence. Its life is made up of the conflicting forces which hold it together by tension and tear it apart as each group seeks eternally to remold it to its advantage. It has the characteristics of an organism, in that it has a lifespan over which its characteristics change in some respects and remain stable in others. One can define its structures as being at different times strong or weak in terms of the internal logic of its functioning. (Wallerstein1976:229)

This definition highlights the living textuality of the system as a simultaneously structured and structuring framework that is also open to the continual restructuring of the framework itself. Moreover, world-systems theory asserts that all systems, even those previously perceived as mutually and markedly remote, increasingly influence, dominate, parody, translate, and subvert one another.

One of the most explicit connections between world-systems theory and the concept of positionality as it relates to translation is rooted in an appeal to transnationalism. An essential component of Homi Bhabha's conception of culture discussed below, transnationalism's bearing on systems theory is often overlooked or underestimated. In terms of positionality, transnationalism reminds us "the frameworks for cultural process relate differently to territoriality. As the state is in itself an organization of territory, this is the framework in which there is the greatest vested interest in spatial definition of culture" (Hannerz117). Demarcations of "borders" "between" cultures or designations of "otherness" as differentiated from the culture of the Self are therefore artificial constructs based on arbitrarily determined divisions between nation states, reflecting once again the problematic nature of conceiving the translator's position as spatially contingent.

\section{Centre and Periphery}

Systems theory has also extensively explored the idea of the "periphery," specifically in its contrasting and complementary relation to the "centre." It is therefore of further use 
in theorizing the translator's position, so often associated with the "periphery." The relationship between the centre and the periphery within a system, as reflected in the concepts of "canonicity" and "non-canonicity" within specifically literary systems, is essential to the continual restructuring of systems and normally conforms to the following pattern:

phenomena in the center are gradually driven towards the periphery and remain there as new phenomena arise in the center - and may sometimes even be those of the periphery. But when these phenomena change positions they rarely remain the same: in the periphery, they often lose their original functions while remaining materially unchanged, "petrified" so to speak. And vice versa. Consequently, while new procedures and initiatives are encouraged in primary [central] activities, secondary [peripheral] ones demand maximum perseverance of sanctioned patterns. This can be put the other way round, too: when one tries new procedures which violate convention, one works per definition within the framework of primary activity and vice versa. (Even-Zohar 1978:16)

Even-Zohar's description points out several very important aspects of positionality as it is constructed in systems theory. Although the term "periphery" proves to be problematic from a purely translation studies approach, in which it implies a subordinate position, it does not present as many issues when viewed through the lens of systems theory, in which positionality is not fixed. Instead, systems are in a constant state of flux because they allow for shifts in positionality, i.e. from the periphery to the centre and vice versa. A state of centrality or peripherality is never complete, permanent, or definitive. On the contrary, systems theory requires that no sub-systemic group or behaviour is absolutely or perpetually peripheral, as such a failure to integrate, implying a failure to approach the centre, would signify complete separation from the system. Alternatively, all members of a system, even if relatively firmly situated in the centre for a given time, are either directly or indirectly networked to "peripheral" or non-normative affiliations by virtue of the fact that such peripheral components exist within their system and thus they are not wholly removed from them.

This shifting positionality between the centre and the periphery highlights the asymmetrical power differentials involved in the continual formulation of systems, whether they are cultural, linguistic, societal, or ideological. Unbalanced power 
differentials are therefore at play at both intersystemic and the intrasystemic levels. The asymmetries between "dominant" (central) and "marginal" (peripheral) cultural systems are crucial to the experience of intercultural encounter, especially as seen in the attempt to enact shifts in the balance of peripheral-central structures through translation. It is important to note, moreover, that Even-Zohar does not succumb to the reductive and regrettably common location of translation as existing on the periphery. Instead, he rather astutely notes that "the position of this system [translated literature] is a shifting one" (1978:19), thoroughly pervading systemic constructs, all the while being actively engaged in performing shifts to and from both the centre and the periphery. This means that translation is fully capable of achieving status as a central activity at certain times and in certain situations. Although translators deal with the encounters with otherness that occur on the periphery and themselves enact shifts between centre and periphery, the ideological position of translation itself is not necessarily a peripheral one.

\section{In Between}

Having surveyed systems theory on a very broad scale, considering both intersystemic (world-systems theory) and intrasystemic (centre-periphery shifts) levels, it is possible to interrogate spatial metaphors for the translator's position in a more informed and nuanced way. In her analysis of the "in between" metaphor, for example, Maria Tymoczko (2003) illustrates just how productive employing a systems theory approach to spatial metaphors can be. Specifically, she demonstrates how locating the translator "between" two cultures implies a complete removal from both cultural systems, which falls prey to the romantic idea of a translator free from allegiances to any culture. Such transcendence is not possible because, as the "sociological turn" has highlighted, the translator is inextricably situated within a cultural, societal, and historical context and cannot be removed from the ideological system of that context. Even if the existence of a space wholly outside of or rigidly "in between" cultures were possible, the translator is incapable of traveling to such a space because his or her ideologically conditioned perspective prohibits extrication from cultural embeddedness. Rather than transcending both cultural and linguistic systems and entering a space "in between" them, the translator operates in a space of overlap between the two systems.

Moreover, the attempt to position the translator in between and therefore outside of cultural systems strips translation of its ideological stance, whereas translation is 
inherently "motivated and determined by the translator's cultural and ideological affiliations as much as or even more than by the temporal and spatial location that the translator speaks from" (Tymoczko183). What can therefore be learned from the "in between" metaphor is that, in light of the necessarily ideological and cultural embeddedness of the translator, there is no "in-between." The space of intercultural encounter does not involve a clear-cut boundary between cultures, much less any kind of space between them. Rather, the space in which the Self encounters otherness is more accurately conceived of as a space of overlap between systems. The translator's position involves the navigation of such areas of overlap between linguistic, cultural, and ideological systems and is accordingly simultaneously embedded in (rather than outside of) them all. Viewing the translator's positionality through the lens of systems theory therefore both elucidates the problems involved in conceiving of a space "in between" cultures and highlights the translator's situatedness within linguistic, cultural, and ideological systems.

\section{Third Space}

In his otherwise insightful and influential work, The Location of Culture (1994), Homi Bhabha employs the trendy but questionable "in between" spatial metaphor, as well as several others, to introduce one of his own that he calls the "Third Space." The pervasiveness of mixed metaphors leads to conflicting imagery in Bhabha's work, weakening his argument. In particular, his use of "in betweenness," while appealing to the terminological vogue of spatial metaphors, is a peculiar way of approaching his own more operative theory of the hybrid Third Space because the two concepts are in many ways contradictory. Through alternating characterizations of the "Third Space" as a "split-space' of enunciation" (56), or an "interstitial" or "in-between" space that is also somehow grounded in cultural "hybridity," Bhabha's imprecise and inconsistent terminological choices make it difficult to define the concept of the "Third Space" in any concise or encompassing way.

Kate Sturge (2007) has been more or less successful in grappling with the Third Space theory, explaining that, because cultural systems and identities are unstable and undergo hybridization, Bhabha views culture as constituted through translation. Translation

according to Bhabha therefore involves the "constant exchange and adaptation between linguistic cultural strands or traditions ...not a traffic between wholes but a process of 
mixing and mutual contamination, and not a movement from 'source' to 'target' but located in a 'third space' between the two" (Sturge 12). Here, we see the association of the "Third Space" metaphor with the problematic notion of the "in between," and moreover we find that it merely reiterates the reciprocal and continual nature of intercultural influence already proposed by Bourdieu's habitus as well as more general concepts of systems. Thus far, the Third Space does not appear to offer productive contributions to theorizing the translator's positionality.

However, if we move beyond the academic compulsion to identify and classify, viewing the Third Space in its more operative sense may prove more useful. Rather than attempting to decipher any precise definition of this ambiguous spatial metaphor from Bhabha's discourse, a consideration of the function of the Third Space produces insightful contributions to a re-examination of positionality. In particular, the experience of the Third Space can provide creative and cultural stimulation, but it is also filled with tensions precipitated by the confrontation of the Self with the Other. For Bhabha, confrontation with the hybridized periphery of one's own cultural system "where cultural differences 'contingently' and conflictually touch, becomes the moment of panic which reveals the borderline experience" (Bhabha 296). Conflicts with the Other, both physical and psychological, destabilize the identity of the Self, which can be both edifying and frightening.

What results is what Doris Bachmann-Medick calls the "third condition" (2009:34), which she relates to the experience of displaced migrants, and characterizes with an overwhelming and inescapable sense of uncertainty. This notion of the "third condition" concurs with Mary Louise Pratt's (1991) characterization of the spaces of overlap between cultural systems as sites of violent confrontation between asymmetrical power differentials. Whereas Bhabha describes a tumultuous internal conflict involving a confusing and painful crisis of cultural identity, Pratt expands the notion to an external level, demonstrating how intercultural encounters such as those provoked by translation have the power to impact real physical and political conflicts between groups. The Third Space therefore emphasizes the need to eschew overly idealistic conceptions regarding intercultural encounter. Because of the need to navigate confrontations between Self and Other, both on a personal and a systemic level, the translator's position within a 
hybridized space of overlap between linguistic, cultural, and ideological systems can be a frightening one.

The "Third Space" metaphor therefore offers a sobering reminder that the translator's position is not always a pleasant one. To be sure, many who are drawn to translation are also drawn to intercultural encounters because of their potential for cultural stimulation, exchange, and revitalization, and as such translators often enjoy the tensions of the Third Space even if others may not. However, translators must still grapple with the fact that the spaces of systemic overlap can challenge the ideological systems in which their identities (and those of their source and target readers) are grounded. Although it may be a stimulating experience for translators attracted to the third condition tensions of intercultural encounter, the act of translation itself provides an intercultural encounter for readers that might not find the confrontation with otherness (and the resulting challenge to their own systemic ideologies and constructed identities) stimulating so much as disturbing. Translators, too, might unwillingly experience the third condition when faced with an intercultural encounter that is more ideologically confrontational than they find enjoyable, especially because they do not always have the privilege of choosing what it is they translate. Translation projects involve varying degrees of ideological conflict between differing systems. The greater the degree of intersystemic conflict, the greater the challenge to the translator's ideology and identity, and therefore the greater the possibility that he or she will have a disturbing experience in the Third Space.

\section{Travel and Migration}

Reflecting the issues of translator agency in terms of text selection (as opposed to text assignment), several spatial metaphors associating translation with travel have differing connotations. Translation as a "carrying across" is deeply linked to the image of the translator as a "traveler" or a "migrant" because the translation of local knowledge before the modern era often involved the physical crossing of space, presupposing travel to a new place. However, the "migrant" label again connotes a marginalized translator, relegated to the position of an "outsider" who is culturally displaced rather than engaged. By contrast, the related and less negatively connotative metaphor of the traveler implies a more active translator with a form of agency, specifically in terms of the "relative mobility of translators, coupled with variable directionalities within networks" (Pym174). 
Travel is a luxury not afforded to everyone, and whereas migration is generally conceived as a unidirectional act, usually undertaken out of necessity, the kindred act of travel is more representative of the translator's voluntary journeying behaviours.

In particular, the translator-as-traveler has the agency to choose to travel, to select the destination, and, ultimately, to return home. The traveler metaphor therefore reflects the translator's active and intentional efforts to encounter otherness as well as the predominantly reciprocal nature of such encounters. The traveler, unlike the migrant, is able to return to his or her homeland. By making this return trip, the translator brings back some remnants of his or her confrontation with otherness. The translator's representation of this intercultural encounter has the potential to influence and inform the translator's "native" culture, or at least his or her own understanding of the Self.As Doris Bachmann-Medick points out, this kind of perspective on the translator as a traveler across cultures can help to replace "our habituated notion of culture as a location of solid belonging and coherence" with "a notion of culture as translation, transition and development" (2009:34). The reciprocity of the flow of information involved in the translator's active, intentional travel can help mitigate antagonistic or hegemonic elements of the opposition between the Self and the Other. The translator's ability to travel across cultures and to navigate further systems allows for recurrent encounters with otherness and resulting re-examinations of the Self, a process which expands and enriches the translator's own ideological associations.

\section{Contact Zone}

Mary Louise Pratt's concept of "contact zones" as "social spaces where cultures meet, clash, and grapple with each other, often in contexts of highly asymmetrical relations of power, such as colonialism, slavery, or their aftermaths as they are lived out in many parts of the world today" (1991:34) is indicative of the areas of overlap between systems. More specifically, though, Pratt frames intercultural encounters within the context of colonialism. Borrowed from linguistics' idea of a "contact language" as an improvised language developed to facilitate communication between speakers of different languages, Pratt's "contact zone" foregrounds the "interactive, improvisational dimensions of colonial [and all intercultural] encounters" and emphasizes "how subjects are constituted in and by their relations to each other" (2007:8). The contact zone is a space of 
reciprocity between cultures, of "copresence" and interaction, producing interlocking understandings and practices.

Because Pratt's discourse is very much grounded in a postcolonial perspective, the contact zone involves reciprocity but not necessarily symmetry. The potential for amicable and harmonious cultural exchange often gives way to characterizations of the contact zone as a predominantly violent place, "involving conditions of coercion, radical inequality, and intractable conflict" (2007:8). She even posits that the discourse of travel hinges on a desire to take possession of the Other, ideally "without subjugation and violence" (Ibid. 56), although these peaceful desires are rarely fulfilled in actual practice. Pratt therefore highlights the imbalance of power differentials inherent to intercultural encounter through a markedly imperialistic example. Thus the "contact zone" offers a useful characterization of spaces of systemic overlap among cultures, emphasizing the necessarily interactive and reciprocal nature of intercultural encounter, but also the asymmetrical power differentials involved. ${ }^{6}$ In terms of translation, although the notion of a physical contact zone is not sufficient for an ideological framing of positionality, it does reflect the fact that the shifts between centre and periphery enacted by translation necessarily involve the navigation of power differentials.

\section{Border Cultures}

Another metaphor that has been used to conceptualize the space of intercultural encounter is that of the "border culture" (cf. Robinson27-30) or the "Borderlands" (cf. Anzaldúa 1987). This concept is rooted in the behaviours of communities that live in socalled "frontier regions," usually located at national borders, where intercultural encounter is most explicit and overt. In these regions, cultures "tend to be diglossic or polyglossic and thus produce intermediaries" and are often mixed, "be it through mixed marriage, mixed education or mixed habitation" (Pym105). The "border culture" is therefore more than a space of overlap or encounter between cultures, but instead the site of a multilingual, multicultural, and often multinational system produced through

${ }^{6}$ See the section on "Reciprocity, the third culture and cybertravel" in Michael Cronin's Across the Lines: Travel, Language, Translation (2000:145-157) for further discussion of the issue of symmetrical reciprocity in translation. 
reciprocal and interactive intercultural encounter. The space of overlap between systemic peripheries therefore involves mutual exchange and serves to hybridize cultural systems.

In terms of translation and positionality, the concept of the border culture can be misleading in several ways. First, while acknowledging spaces of overlap at the periphery, it maintains a strict boundary between cultures as distinct identities. Taking the border between the United States and Mexico, for example, a hybridized American-Mexican "border culture" may exist, but "American culture" and "Mexican culture" are still conceived of as distinct entities outside of this "frontier region." Second, the border culture is itself generally presented as a "new" and separate cultural system that "bridges" the border between two different cultures "in a variety of peripheralized and often brutalized ways that may nevertheless offer new avenues for cultural development" (Robinson28). This view ignores the fact that, as border cultures themselves demonstrate, cultures are always fluid and changing, and therefore cannot be conceived of as monolithic or fully distinct from other cultures.

Third, the border culture metaphor again refers to positionality in translation in strictly physical and spatial terms. The "borderland" implies being on the rim, at the furthest extremity of cultural identity, but in reality this kind of cultural mixing of the borderland can be found everywhere intercultural encounters take place and often contributes to the continual (re)structuring of cultural systems. Border cultures are not only situated at the arbitrarily determined borders between countries, states, or principalities. In fact, the kind of cultural hybridization characteristic of the borderlands is actually "predominantly a phenomenon of the city" (Pym105) because the abundance of cultural systems present in such urban settings leads to increased opportunity for intercultural encounter. Indeed, "languages [and cultures] coexist or jostle for space with no regard for the borders drawn on maps" (Sturge11; cf. Lambert63-74), so translation in the borderlands does not occur "between" pairs of distinct, coherent languages at all. Instead, translators navigate through hybridized and interrelated cultural and linguistic systems that are in the continual process of further hybridization.

\section{Hybridity}

These spatial metaphors for the position of the translator are all in some sense associated with the periphery, but even more so they lead us away from a strictly physical or spatial 
concept of positionality and toward an ideological construct of systemic hybridity. Although he clutters his argument with conflicting spatial imagery, Homi Bhabha recognizes the importance of hybridity in locating culture by using it to characterize his spatial metaphor of the Third Space. For Bhabha, culture is both "transnational and translational" (5): it is not defined by national borders but rather constructed through the intercultural encounter of translation, which leads cultural systems to be in a continual process of intermingling and hybridization. This notion of cultural hybridity denies the possibility of any kind of stable differences between cultures and languages.

Translation in the traditional sense, in which the translator "bridges" two distinct cultural and linguistic systems, is rendered impossible. According to Bhabha, culture is therefore "untranslatable," and rather is itself constituted by translation, "not because each culture is unique, special, unlike all others, but because it is always mixed with other cultures, because culture always overflows the artificial borders that nations set up to contain it" (Robinson27). Translation therefore reflects "a dynamic concept of culture as a practice of negotiating cultural differences, and of cultural overlap, syncretism and creolization" (Bachmann-Medick 2006:37). The translator's position is characterized by the same dynamism, interactivity, and hybridity. Because the translation activities found in border cultures are not exclusive to physical borderlands, but instead occur wherever intersystemic encounters are found, translation as an engine for systemic hybridization is not just a characteristic of the periphery, but of culture in general.

Whereas systems theory has been productive when interrogating the shortcomings of viewing positionality in translation in terms of spatial metaphors, it informs but also supports notions of hybridity as useful to conceptualizing the translator as occupying an ideological position. Specifically, systems are not fixed or monolithic but rather hybrid because they are constantly changing through intersystemic encounters. In addition to the fluidity of the periphery, the largely stable systemic centre is also subject to outside influence and thus has the potential to change, even if by comparison such change is generally a slower process, precipitated by more significant challenges to cultural identity, involving more extensive translational activity and a deeper penetration of otherness into cultural consciousness. The otherness that enters a system via its permeable borders manifests itself in a form of hybridity that has the potential to gradually make its way further and further toward the system's centre. We must therefore view any linguistic, 
cultural, or ideological system "as normally being contradictory, loosely integrated, contested, mutable, and highly permeable" (Sewell 53; cf. Brightman 1995) not only on its fluid periphery but also at its very core. To some extent any system therefore necessarily possesses an element of inner hybridity because, as dynamic, heterogeneous structures, systems are never fixed, even when characterized by a largely stable core. They are rather indeterminate and exceedingly open to influence from other systems. ${ }^{7}$

Culture is a conceptual construct and the formulation of cultural systems is a continual process of re-articulation precipitated by encounters with otherness. In reexamining the cultural Self through encounters with the Other, the Self is no longer the same Self it was before that encounter, but a reformulated one. Even when otherness is rejected rather than incorporated, the identity of the Self is reformulated as a direct oppositional reaction to encountering the Other and as such is constructed based on perceived notions of otherness. Because such (re)translation of the Self is a necessary response to encounters with systemic otherness, the perspective of the translator is necessarily reflexive. Indeed, objectivity is thus rendered impossible, as "every version of an 'other,' wherever found, is also the construction of a 'self"' (Clifford23). And, just as systems are continually formulated through shifts between centre and periphery, the introduction of "otherness into a system's webs of significance, and the reformulation of systemic ideology as precipitated by intercultural encounter, so this kind of perpetual (re)translation of the Self also occurs at the level of the individual.

The translator is one type of individual who regularly and intentionally encounters otherness and therefore even more actively engages in the reformulation and retranslation of the Self. Through such intercultural practices as translation, "Self and other are no longer experienced as an opposition; instead the experience of multiple cultural allegiances and fractured identities allows otherness and alienation to reach deep down into the experience of the self' (Bachmann-Medick 2009:34). For the translator, then, the purpose of encountering the Other is not so much to understand the Other as to understand the Self. To be sure, complete understanding of the Self is impossible, just as is complete understanding of the Other. But the goal of translation is not complete

\footnotetext{
${ }^{7}$ For a brief but comprehensive overview of cultural translation and the breakdown of self/other and source/target dichotomies and other highly productive perspectives on translation drawn from the field of ethnography, see Kate Sturge's Representing Others: Translation, Ethnography and the Museum (2007), especially the second chapter, "Translation as Metaphor, Translation as Practice."
} 
understanding; it is continual reformulation and systemic enrichment of the Self through expanding networks of affiliation and hybridizing cultural identity. Encounters with the foreign serve to further hybridize the Self in this way, adding networks of association to an increasingly complex identity.

\section{Reformulating the Positionality of the Translator}

What, then, can we say about the position of the translator? The value of the various problematic spatial metaphors commonly employed in discussions of positionality in translation cannot be assumed and is instead contingent upon critical scrutiny. We have seen that, since the translator is inextricably embedded in an ideological context, positionality in translation is ideological rather than spatial, not necessarily bound by the translator's physical or temporal location. Nonetheless, beyond the theoretical problems these popular spatial metaphors raise, their pervasive use by translation scholars implies that they might offer some productive concepts in the effort to theorize the translator's position. In particular, the peripherality traditionally and conventionally associated with translation is not inherent to the practice itself, but is rather a characteristic of the spatial parameters of the most direct encounters between cultural systems. This space is not "in between" cultures because it is not possible to transcend systemic structures, which are not monolithic but rather interconnected. Therefore, instead of distinct boundaries between cultural systems we find that they overlap and engage in reciprocal (although not necessarily symmetrical) interaction and influence.

In light of the ideological structure provided by systems theory, the translator's positionality might be most productively associated with the idea of travel, but not in the sense of physical movement through space. Rather, the translator navigates ideological territories, traveling through (but not "between" or "across") overlapping systems. Such a journey forces the traveler to confront both the similarities and the differences between the Self and the Other. This confrontation with otherness breaks down the illusion of a stable identity and as such may be an unsettling experience, but it can also be a culturally stimulating and exhilarating one. The translator then carries his or her experience back through layers of systemic overlap and brings them into his or her own "native" system by re-presenting the encounter with otherness, thereby eliciting some measure of re-examination and reformulation of the Self at both a systemic and a personal level. The act of translation and the reception of a translated text therefore both 
constitute intercultural encounters that prompt a continual formulation of the Self on the level of the individual and ultimately at the level of the system, resulting in hybrid and dynamic cultural identities.

The position of the translator cannot be properly conceived in terms of physical space, but is rather an ideological construct more productively thought of in terms of the translator's systemically hybrid identity. In this way, translation is removed from the periphery in the traditional sense, thereby disconnected from the marginal, subordinate, or outsider position it connotes. Instead, the translator seeks out the ideological borderlands, encountering otherness wherever it may occur, whether in overlapping intersystemic peripheries or as an agent of intrasystemic transfer between periphery and centre. The translator's position is thus a powerful and shifting one, navigating a network of systems that are ideological and conditioned as well as hybrid and dynamic. In this positional context, the translator negotiates and provokes continual retranslation of the Self, in both the collective and the individual sense, specifically through active engagement in intercultural encounters with the Other. 


\section{REFERENCES}

Anzaldúa, Gloria.Borderlands/La Frontera: The New Mestiza. San Francisco: Spinsters/AuntLute, 1987.

Bachmann-Medick, Doris. "Meanings of Translation in Cultural Anthropology." Translating Others. Ed. Theo Hermans. Vol. 1. Manchester: St. Jerome Publishing, 2006. 33-42.

-----. " $1+1=3$ ? Intercultural Relations as a "Third Space." Critical Concepts: Translation Studies. Ed.Mona Baker. Vol. 2. London: Routledge, 2009. 31-45.

Bassnett, Susan and André Lefevere. "Introduction: Proust's Grandmother and the Thousand and One Nights: The 'Cultural Turn' in Translation Studies." Translation, History and Culture. Eds. Susan Bassnett and André Lefevere. London and New York: Pinter, 1990. 1-13.

Benjamin, Walter. "The Task of the Translator: An Introduction to the Translation of Baudelaire's Tableaux Parisiens.'Illuminations. New York: Schocken Books, 1969. 6982.

Bhabha, Homi K. The Location of Culture. New York \& London: Routledge, 1994.

Bourdieu, Pierre. Outline of a Theory of Practice. Cambridge, U.K.: Cambridge University Press, 1997.

Brightman, Robert. "Forget Culture: Replacement, Transcendence, Relexification." Cultural Anthropology 10.4 (1995): 509-46.

Clifford, James. "Introduction: Partial Truths." Writing Culture: The Poetics and Politics of Ethnography. Eds. James Clifford and George E. Marcus. Berkeley: University of California Press, 1986. 1-26.

Cronin, Michael. Across the Lines: Travel, Language, Translation. Cork, Ireland: Cork University Press, 2000. 
Even-Zohar, Itamar. Papers in Historical Poetics. Tel Aviv: Porter Institute, 1978.

-----. "Translation and Transfer." Poetics Today [Special Issue on Polysystem Studies], 11.1 (1990): 73-78.

------. "Polysystem Theory (Revised)." Papers in Culture Research. Tel Aviv: Unit of Culture Research, 2010.40-50.

Geertz, Clifford. The Interpretation of Cultures: Selected Essays by Clifford Geertz. New York: Basic Books, 1973.

Gruesz, Kirsten S. Ambassadors of Culture: The Transamerican Origins of Latino Writing. Princeton, N.J: Princeton University Press, 2002.

Hannerz, Ulf. "Scenarios for Peripheral Cultures." Culture Globalization and the World System: Contemporary Conditions for the Representation of Identity. Ed. Anthony King. Minneapolis: University of Minnesota Press, 1997. 107-28.

King, Anthony D. "Introduction: Spaces of Culture, Spaces of Knowledge." Culture Globalization and the World System: Contemporary Conditions for the Representation of Identity. Ed. Anthony King. Minneapolis: University of Minnesota Press, 1997. 1-18.

Lambert, José. In Dirk Delabastita, Lieven D’Hulst and Reine Meylaerts (eds.), Functional Approaches to Culture and Translation: Selected Papers by José Lambert. Amsterdam: John Benjamins Publishing Company, 2006.

Pratt, Mary Louise. “Arts of the Contact Zone.” Profession (1991): 33-40.

-----. Imperial Eyes: Travel Writing and Transculturation. $2^{\text {nd }}$ ed. London: Routledge, 2007.

Pym, Anthony. Method in Translation History. Manchester, UK: St. Jerome Publishing, 1998.

Robinson, Douglas. Translation and Empire: Postcolonial Theories Explained. Manchester, UK: St. Jerome Publishing, 1997. 
Sewell, William H. "The Concept(s) of Culture.” In Victoria E. Bonnell and Lynn Hunt (eds.), Beyond the Cultural Turn: New Directions in the Study of Society and Culture. Berkeley: University California Press, 1999. 35-61.

St. André, James, ed. Thinking Through Translation with Metaphors. Manchester, UK: St. Jerome Publishing, 2010.

Sturge, Kate. Representing Others: Translation, Ethnography and the Museum. Manchester, UK: St. Jerome Publishing, 2007.

Tymoczko, Maria. "Ideology and the Position of the Translator: In What Sense is a Translator 'In Between'?" Apropos of Ideology: Translation Studies on Ideology - Ideologies in Translation Studies. Ed. María Calzada Pérez. Manchester, UK: St. Jerome Publishing, 2003. 181-201.

Wallerstein, Immanuel. The Modern World-System: Capitalist Agriculture and the Origins of European World-Economy in the Sixteenth Century. New York: Academic Press, 1976.

-----. "The National and the Universal: Can There Be Such a Thing as World Culture?" Culture Globalization and the World System: Contemporary Conditions for the Representation of Identity. Ed. Anthony King. Minneapolis: University of Minnesota Press, 1997. 91-105.

Wolf, Michaela. "The sociology of translation and its 'activist turn." Translation and Interpreting Studies 7.2 (2012): 129-143. 